\section{New mental health services}

\section{for deaf patients}

A new service promises to break down some of the barriers to mental health care faced by people with hearing losses.

At Canada's first tertiary care Mental Health Services for the Deaf (MHSD) at Regional Mental Health Care (RMHC) in London, Ont., services are provided by hearing psychiatrist Dr. Elizabeth Lock and by Canada's only deaf clinical psychologst, Dr. Cathy Chovaz McKinnon, along with a part-time nurse. Services are available in American Sign Language (ASL), total communication and in spoken English and French. Presently, the service isn't offered in La Langue des Signes Québécoise (LSQ). Interpreters and intervenors are used when needed.

Lock says physicians don't receive regular training in treating deaf patients so "they are not aware of why the services are inaccessible."

Patients who are deaf, deafened, hard of hearing and deaf-blind face tremendous barriers in accessing health care in general and mental health services in particular.

Commonly, when deaf patients attempt to communicate in sign language, "they are often mistaken by medical professionals to be exhibiting 'bizarre behaviours,' 'physical agitation' or 'violent gestures."' Because they are often misunderstood, Lock says "deaf patients are frequently misdiagnosed, not communicated with, not given informed care" and have "unnecessarily long hospital stays."

Lock says many people think deaf people "should" or "can" communicate in English or French. Yet for many reasons most individuals who have been deaf since birth do not acquire facility in English, which is also often their second language. Lock stresses lip reading is also problematic because only $25 \%-30 \%$ of English sounds are visible externally. This makes conversation difficult to grasp, especially if one has never heard spoken language.

Lock adds that few physicians are aware of Supreme Court ruling (EIdridge v. British Columbia, 1997) or know how to get a certified interpreter. Certified interpreters must be provided

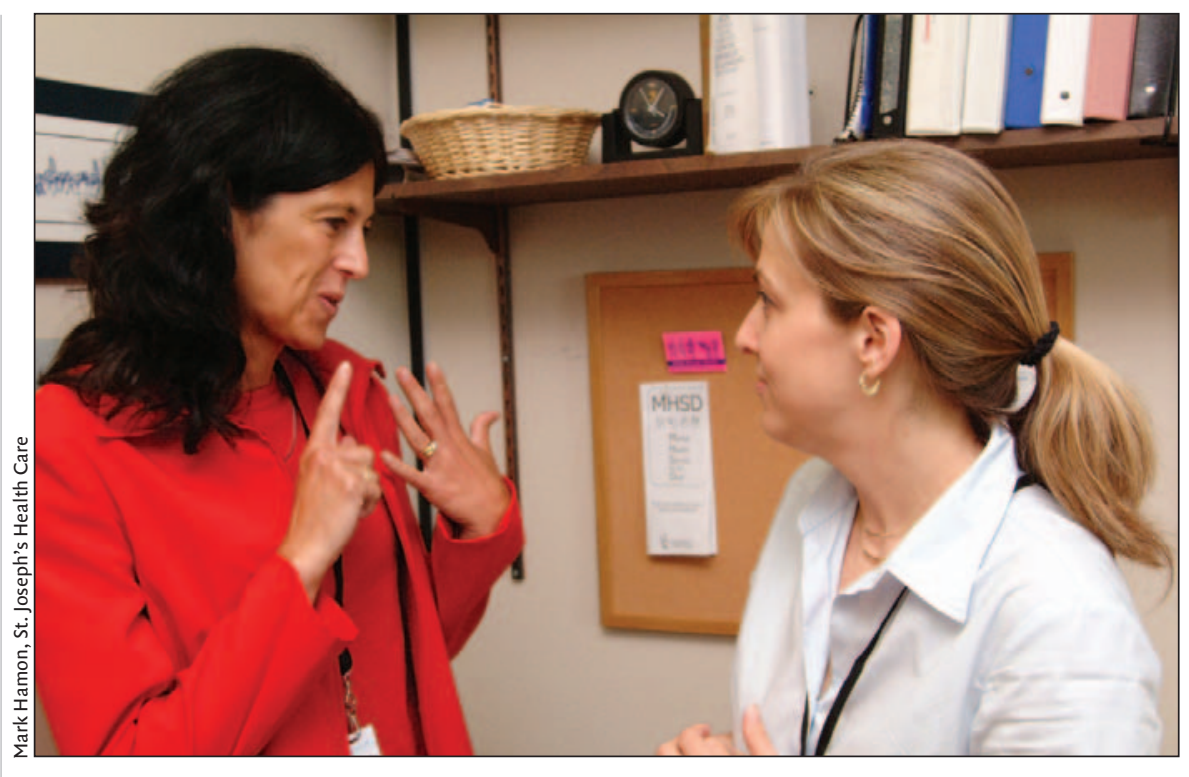

Dr. Cathy Chovaz McKinnon (left) signing with Dr. Elizabeth Lock

for deaf patients; thus laypersons and families should not be used.

Miscommunication "can result in admissions to psychiatric facilities when there is no psychiatric problem," says Lock. In "such cases, the medical problem can be missed altogether." Similarly, when deaf people write answers on paper, they may do so using ASL grammar but English words," which can produce further misunderstanding or misdiagnosis".

Common misdiagnoses are psychosis, hyperactivity, ADHD or mental deficiency

Currently, MHSD offers tertiary care for deaf, deafened, hard of hearing and deaf-blind individuals in southwestern Ontario. This area is densely populated and London is home to Robarts School for the Deaf. An estimated 7000 persons will need the services in London. MHSD provides in- and outpatient mental health assessment and treatment and will provide mental health care to individuals with a serious mental health disorder. MHSD hopes eventually be able to service other parts of Canada.

"We guide our care based on the level of need and strive to work with family doctors, specialists and community services to provide shared care type of service. Our goal is that of mental wellness and to provide ethically, linguistically and culturally appropriate quality service," Lock advises.
MHSD also offers learning and research opportunities for University of Western Ontario medical, psychology and nursing students.

Both Lock and Chovaz McKinnon worked for years to create similar programs in different areas of Canada. Dr. Sandra Fisman, chair and chief of the department of psychiatry for St. Joseph's Health Care, London Health Sciences Centre and University of Western Ontario brought both professionals to RMHC London. - Lynne Swanson, London, Ont.

DOI:Io.I503/cmaj.o6r $35^{2}$

\section{Decline in breast cancer}

\section{since HRT study}

A lthough the causal link hasn't been conclusively established, US researchers say there's been a remarkable decline in breast cancer rates since fewer women began taking hormone replacement therapy (HRT) to alleviate the symptoms of menopause.

The overall incidence of breast cancer in the US declined $7 \%$ between 2002 and 2003, while the number of women aged 50-69 diagnosed with estrogen receptor positive (ER-positive) breast can- 